Review

\title{
A Review of Forward-Dynamics Simulation Models for Predicting Optimal Technique in Maximal Effort Sporting Movements
}

\author{
Stuart A. McErlain-Naylor ${ }^{1, *(1)}$, Mark A. King ${ }^{2}\left(\mathbb{D}\right.$ and Paul J. Felton ${ }^{3}$ (i) \\ 1 School of Health and Sports Sciences, University of Suffolk, Ipswich IP4 1QJ, UK \\ 2 School of Sport, Exercise and Health Sciences, Loughborough University, Loughborough LE11 3TU, UK; \\ M.A.King@lboro.ac.uk \\ 3 School of Science and Technology, Nottingham Trent University, Nottingham NG11 8NS, UK; \\ paul.felton@ntu.ac.uk \\ * Correspondence: s.mcerlain-naylor@uos.ac.uk
}

check for updates

Citation: McErlain-Naylor, S.A.; King, M.A.; Felton, P.J. A Review of Forward-Dynamics Simulation Models for Predicting Optimal Technique in Maximal Effort Sporting Movements. Appl. Sci. 2021, 11, 1450.

https: / doi.org/10.3390/app11041450

Academic Editor: Redha TAIAR

Received: 23 December 2020

Accepted: 2 February 2021

Published: 5 February 2021

Publisher's Note: MDPI stays neutral with regard to jurisdictional claims in published maps and institutional affiliations.

Copyright: (c) 2021 by the authors. Licensee MDPI, Basel, Switzerland. This article is an open access article distributed under the terms and conditions of the Creative Commons Attribution (CC BY) license (https:/ / creativecommons.org/licenses/by/ $4.0 /)$.

\begin{abstract}
The identification of optimum technique for maximal effort sporting tasks is one of the greatest challenges within sports biomechanics. A theoretical approach using forward-dynamics simulation allows individual parameters to be systematically perturbed independently of potentially confounding variables. Each study typically follows a four-stage process of model construction, parameter determination, model evaluation, and model optimization. This review critically evaluates forward-dynamics simulation models of maximal effort sporting movements using a dynamical systems theory framework. Organismic, environmental, and task constraints applied within such models are critically evaluated, and recommendations are made regarding future directions and best practices. The incorporation of self-organizational processes representing movement variability and "intrinsic dynamics" remains limited. In the future, forward-dynamics simulation models predicting individual-specific optimal techniques of sporting movements may be used as indicative rather than prescriptive tools within a coaching framework to aid applied practice and understanding, although researchers and practitioners should continue to consider concerns resulting from dynamical systems theory regarding the complexity of models and particularly regarding self-organization processes.
\end{abstract}

Keywords: torque-driven; optimization; parameters; evaluation; dynamical systems theory; constraints; self-organization; performance; individual; complexity

\section{Introduction}

The identification of optimum technique for maximal effort sporting tasks, especially specific to an individual, has been called the "holy grail" of sports biomechanics and is one of the greatest challenges within the discipline [1]. Sports biomechanics investigations have mostly adopted a reductionist perspective to identifying characteristics (e.g., anthropometrics, strength, technique) associated with a performance outcome [2,3]. The inferential statistical approaches used typically either compare group means (e.g., elite vs. sub-elite, pre vs. post-intervention) or assess (intra- or interindividual) correlations between biomechanical characteristics and the performance outcome [3]. Application of conclusions drawn from interindividual comparisons/relationships to any specific individual is limited [4,5]. Likewise, intraindividual experiments are dependent upon the individual's current technique, which may not be optimal [2].

Unlike experimental studies, a theoretical analysis using computer simulation allows complete control of the testing environment, in which individual factors can be systematically isolated and perturbed independently of potentially confounding variables [4]. In forward-dynamics simulation modeling, the forces driving a mathematically modeled system are specified, and the resulting motion is calculated. This enables parameters to be 
perturbed in search of an "optimal" movement solution for the specific individual given various constraints and assumptions [6,7]. The aim of this paper is to provide a critical review of the literature related to forward-dynamics simulation models of individual-specific maximal effort sporting movements. A secondary aim is to provide recommendations regarding future directions and best practices when using such approaches in sports biomechanics research or applied sports settings.

\subsection{Forward-Dynamics Simulation Models}

The development and application of forward-dynamics simulation models typically involve four stages: (1) model construction; (2) parameter determination; (3) model evaluation; (4) model application [8-13]. The first three stages are often an iterative process until the model incorporates sufficient complexity to adequately represent the real physical system (i.e., each time model complexity is changed, the number of individual-specific parameter values to be determined may alter). Early models typically generated equations of motion from first principles using Newton's Second Law [14,15], although software packages utilizing Kane's method [16] to model the dynamical system have become increasingly popular. To run the model, an iterative method (e.g., Euler method or Runge-Kutta) is used to advance the model dynamics over specified time intervals [17]. Model outputs comprise time histories of all calculated variables (e.g., whole-body orientation, linear and angular momentum, joint kinematics and/or kinetics, and possibly joint reaction forces). Once a model has been evaluated, typically by assessing how closely it can reproduce the recorded performances of an individual [9], it can be applied to investigate cause and effect relationships and optimal individual performance [12,13,18-21]. Given the number of assumptions and constraints necessary to model the human body mathematically and computationally, these must be critically reviewed in relation to the true human dynamical system.

\subsection{Dynamical Systems Theory}

In human movement science, dynamical systems theory emphasizes that individual movement patterns are determined by the process of self-organization [22] and the interaction of organismic, environmental, and task constraints [23]. Self-organization processes are those where a pattern at the global level of a system emerges solely from interactions among the lower-level components, using only local information and without reference to the global pattern or imposition by an external ordering influence [24,25]. In human movement, feedback loops, multiple interactions, stochasticity and randomness lead to emergent behaviors, multi-stability and robustness [24]. The combined effects of constraints and self-organization processes channel and shape the outcome of the movement and, ultimately, the performance $[23,26,27]$. Organismic constraints reside within the human system and can be subdivided into structural and functional organismic constraints. Environmental constraints are external to the human system, and task constraints are specific to the task being performed (e.g., its rules and objectives) $[25,26,28]$. Such constraints restrict the possible configurations that a complex system's many degrees of freedom can adopt [29]. In a forward-dynamics simulation, these constraints are mathematically modeled using Newtonian mechanics and assumptions to create a dynamical system (a system of mathematical functions that describe the time dependence of a point or points in geometric space).

While model evaluation provides evidence that a model can replicate a recorded movement pattern, it does not guarantee that any subsequently optimized movement patterns are valid solutions [30]. This has led dynamical systems theorists to debate the efficacy of forward-dynamics simulation models to establish cause and effect relationships or predict optimum technique [1,2]. While forward-dynamics simulation models have been examined holistically using a dynamical systems framework [1], the mathematical representation of constraints and self-organization processes [22,23] are yet to be reviewed. These representations will be critical to the accuracy of any predicted optimal technique for maximal effort sporting movements. This paper will therefore review the four stages of 
development and application of forward-dynamics simulation models and their potential to predict individual-specific optimal technique for maximal effort sporting movements using a dynamical systems theoretical framework.

\section{Review of Model Construction and Parameter Determination}

\subsection{Organismic Constraints}

Within dynamical systems, each organismic constraint can be categorized as a structural or functional constraint [23]. Structural constraints tend to be physical constraints that remain relatively constant between each simulation (e.g., height, body mass and composition, segmental inertia properties, joint range of motion, muscle properties), while functional constraints tend to refer to the time-dependent behavioral aspect of an individual and potentially change within or between simulations (e.g., motivation, fear, focus) [25].

\subsubsection{Structural Constraints Model Complexity}

As a rule of thumb, forward-dynamics simulation models have remained as simple as possible while maintaining sufficient complexity to answer the research question [4]. For instance, Pandy contrasted simple and complex models of walking to show that a simple model (an inverted double pendulum) was able to identify basic features of muscle function during gait, but that a more complex model (3-dimensional, 10-segment, 23-degree-of-freedom musculoskeletal model) was required to discern the functional roles of specific muscles in the movement [31]. Similarly, for jumping, Alexander was able to use a planar two-segment, single muscle model to estimate optimum touchdown conditions for the plant leg in running jumps that were in close agreement with competitive performances [14]. To realistically predict muscular control during jump performances required a three-dimensional model consisting of ten segments and 54 muscle actuators [32] or 17 segments and 46 muscle actuators [33].

It is often claimed that the simpler the model, the easier it is to quantify the contribution of its features to the observed effect $[14,34]$. However, in reality, the complexity of forward-dynamics simulation models are more often limited by computational power and the ability to construct scientifically robust constraints. Forward-dynamics simulation models investigating maximal effort sporting movements have, therefore, typically represented relatively simple planar movements such as bilateral vertical jumps where relatively little error is introduced by the assumptions of planar movement $[9,10]$ or bilateral symmetry $[12,35,36]$. Three-dimensional forward-dynamics models have been restricted to angle-driven models [37] or muscle-driven models with muscle parameters either scaled from values in the literature [32,33] or determined via optimization [38,39]. This has limited their application to neuromuscular coordination, internal loading, and injury risk [38-42], rather than the optimization of maximal effort sporting performance.

\section{Anatomical Constraints}

Most existing whole-body forward-dynamics simulation models are based on a system of linked rigid bodies. Each rigid segment typically represents a body segment and is defined using four inertial parameters: length, mass, mass center location and moment of inertia. To determine accurate individual-specific inertial parameters, regression equations or geometric models have most frequently been used. The regression approach scales parameters from cadaver segments based on simple anthropometric measurements [43-45]. The accuracy of this approach is dependent on the similarity of morphology between the cadavers used and the individual being modeled, which is often limited given the athletic individuals under investigation. Alternatively, geometric models are used to mathematically estimate segmental inertia parameters from a number of anthropometric measurements per segment given an assumed geometric segment shape of uniform density [46-48]. The most frequently used method-that of Yeadon—uses 40 geometrical shapes requiring 95 anthropometric measurements (34 lengths, 41 perimeters, 17 widths 
and 3 depths) [47]. Errors of 2.3\% have been reported for total body mass [47], with segmental densities the only values assumed from literature. While segmental densities can be adjusted within this method to ensure correct total body mass, this may not avoid errors within individual segments. The estimation of segmental inertia parameters may be improved through scanning methodologies such as dual-energy X-ray absorptiometry $[49,50]$. All necessary segmental inertia parameters can be obtained via a combination of areal density and the mass associated with each component (e.g., bone mineral, lean tissue, fat tissue) [50]. These methods may be particularly feasible in future investigations, given the small number of individuals typically participating in simulation studies. Alternatively, gold-standard scanning methods can be used to develop regression methods $[51,52]$ or evaluate existing geometric models [53-57].

The connections between rigid segments (considered to represent the skeleton) are typically modeled as frictionless one degree of freedom "pin" joints where the distal and proximal ends of two connecting segments are joined at a common point. This assumption is a simplification of reality and has been particularly questioned at the shoulder, where motion can occur at four different joints [4]. To overcome this for giant circles on the high bar in gymnastics, a simple viscoelastic representation has been used [58]. Alternatively, a complex finite element model was required to investigate individual muscle contributions to the movement of the shoulder [59]. While the effects of pin-joint assumptions are yet to be systematically investigated within whole-body forward-dynamics simulation models, researchers should recognize that the use of pin joints may neglect the energy-dissipative properties of in vivo compliant joint structures [60-62].

When modeling sporting movements involving an impact, it has become increasingly common to represent the "wobbling mass" within body segments with large amounts of soft tissue using a second rigid segment attached to the first (representing underlying bone) via viscoelastic springs at the proximal and distal ends [63]. This represents post-impact soft tissue displacement by enabling the wobbling mass to displace relative to the rigid segment and has been shown to reduce loading on the system by up to $50 \%$ compared to an equivalent rigid model [64]. The calculation of separate inertia parameters for rigid and wobbling segments requires information on the ratio of bone to soft tissue, typically obtained from cadaver studies [65], although this can be obtained for specific individuals via dual-energy $X$-ray absorptiometry [52]. If values are used from the literature, this ratio can be scaled to the individual using total body mass and percentage body fat $[64,66,67]$. The viscoelastic springs connecting the rigid segments representing the bone and wobbling mass elements were originally represented as linear springs [68], but more recently, damped nonlinear passive springs have been used [69]. As it is not possible to measure the viscoelastic stiffness and damping parameters for these springs, they are often determined using a model driven by experimentally recorded kinematics of the individual. The parameters are varied within set bounds by an optimization algorithm to minimize kinetic and whole-body kinematic differences between simulated and experimental performances [66]. The maximum permissible wobbling mass displacement within shank, thigh and trunk segments during this approach have been $5.0 \mathrm{~cm}, 7.5 \mathrm{~cm}$ and $11.0 \mathrm{~cm}$, respectively $[13,36,60]$. These numbers may be excessive, however, with recent experimental research recording shank and thigh soft tissue displacement during drop landings of up to $1.4 \mathrm{~cm}$ relative to the underlying bone [70]. Furthermore, the frequently cited source for trunk wobbling mass displacement limits is a study on viscera displacement during hopping [71]. The viscera represents only one portion of the trunk wobbling mass, with the remaining component (including skeletal muscle and adipose tissue) likely displacing to a lesser degree than the maximum $8 \mathrm{~cm}$ reported for the viscera in that study. It is additionally unlikely that peak displacements of the various soft tissue elements within the trunk will occur synchronously. The excessive compliance required within wobbling mass representations likely compensates for lack of compliance elsewhere in these models. One possibility is that it reduces the effect of neglecting joint compression when modeling pin joints between adjacent body segments [60]. Finally, more representative wobbling mass 
constraints may be achieved via viscoelastic parameters that vary as a function of the local actuator activation levels or force-velocity characteristics [72-74], and realistic oscillation durations should be ensured.

\section{Strength Constraints}

The force exerted by muscle has predominately been modeled in forward-dynamics simulation models using a muscle-tendon complex to divide the force-producing capabilities of muscle into a contractile component and two elastic elements: a series elastic element and a parallel elastic element [75]. Adopting the muscle-tendon complex approach requires mathematical relationships for each component so that the maximum force-generating capabilities of the individual can be calculated.

While Huxley combined the sliding filament and cross-bridge theories to express the contractile force during muscle contraction at a microscopic level [76], the research focus of forward-dynamics simulation models has seen a macroscopic approach adopted to mathematically modeling the force produced by the whole contractile component as a function of its length, rate of shortening or lengthening, and "neural" activation [77]. The force-length relationship has been modeled as a quadratic function $[9,78]$ or bell-shaped curve [79], representing the ascending limb, plateau region, and descending limb [80,81]. In the concentric phase of the force-velocity relationship, tetanic force decreases hyperbolically with increasing rate of shortening to approach zero at the maximum rate of shortening (modeled as a rectangular hyperbola) [82-84]. Eccentrically, the maximum force increases rapidly to around 1.4-1.5 (tetanic) [85] or 1.1-1.2 (voluntary) [86] times the isometric value, with the increasing rate of lengthening and then plateaus for higher speeds (modeled as an inverted hyperbola) [84]. These differences between tetanic and voluntary contractions are due to reduced neural drive under eccentric and low concentric maximum voluntary contractions [87-89]. The tetanic force-velocity relationship has been corrected for voluntary contractions via a differential activation function increasing from a depressed level at high eccentric velocities to full activation at high concentric velocities $[79,84,90]$. Discontinuity in the transition from eccentric to concentric [82] has been incorporated within the eccentric representation using predictions of the eccentric to concentric slope ratio [76,84,91,92].

The series elastic component has commonly been modeled as a non-damped spring, with force expressed as an increasing function of its length and with a slack length below which no force can be generated [35]. The accuracy of series elastic component parameters has been shown to affect model performance [93], necessitating realistic elastic compliance. The force produced by the parallel elastic component has been assumed to be dependent on the contractile component length but independent of muscle activation [94]. Linear [95], parabolic [96], and exponential [97] functions have all been used to represent the parallel elastic component, although it has often been disregarded [8,9] due to it having an assumed minimal effect during functional joint ranges of motion [98].

The application of structural constraints based on the muscle-tendon complex within forward-dynamics simulation models of maximal effort sporting movements have followed two alternative paths: muscle-driven models and torque-driven models. Muscle-driven models incorporate the effect of each muscle individually using the muscle-tendon complex representation. Although muscle-driven models have been widely used to investigate the function and contributions of individual muscles to different movements [99], their most frequently cited limitation is the difficult selection of realistic individual muscle parameters. Individual-specific muscle parameters, which are required for each component of each muscle-tendon complex, are difficult to determine non-invasively, whereas relying on data from the literature results in parameters that are not specific to any individual. Nonetheless, advances have been made in the scaling of musculo-tendon parameters such as optimal fiber length and tendon slack length for individual-specific models [100-102]. The application of muscle-driven models to investigating individual-specific maximal effort sporting movements is limited at high movement velocities [103] since the optimal performance of these movements is likely to be sensitive to variation in the strength capa- 
bilities of the musculature, as reported in jumping simulations [104]. This is particularly relevant if predicting individual-specific optimal technique is the aim of the research.

Torque-driven forward-dynamics simulation models use torque generators to apply the net effect of all muscles acting across a joint, using a rotational muscle-tendon complex. To achieve realistic joint kinematics and activation dynamics, models have incorporated separate agonist and antagonist (e.g., flexor and extensor) torque generators. This allows for co-contraction, during impact landings, for example [36]. Due to the force-velocity characteristics, co-contraction of flexors and extensors with net-zero joint torque at touchdown leads to increasing extensor torque and decreasing flexor torque as the joint flexion velocity increases. These considerations are important in any activity requiring rapid changes in net joint torque.

Studies using torque-driven simulation models have typically focused on the global performance resulting from the joint torques and kinematics rather than on the role and contribution of individual muscles. Where joint reaction forces are of interest, the individual-specific joint torque can instead be applied as a single "lumped" linear muscle at a specified moment arm [105-107]. A major advantage of torque generators is that individual-specific strength parameters can be readily obtained using an isovelocity dynamometer $[11,79,84,108]$, providing assurance that torques exerted at each joint angle and velocity within any predicted optimal technique are realistic for the individual. This process involves collecting maximal voluntary joint torque data of an individual working with maximal effort against a crank moving at a constant angular velocity over a range of joint angles [79]. The data are then used to determine parameters for each torque generator's contractile component as well as indirectly for the series elastic component. The contractile component torque profile is determined using an optimization algorithm to vary each parameter within the function (i.e., force-length and force-velocity relationships) between physiological upper and lower bounds identified from the literature, minimizing the difference between measured and calculated joint torques $[79,109,110]$. The series elastic stiffness is calculated using maximal dynamometer measures [35], assuming a $4 \%$ tendon stretch [111] in combination with muscle, tendon and moment arm lengths from the literature [112].

Forward-dynamics simulation models of maximal effort sporting movements have predominately adopted monoarticular representations, where the calculated contractile component torque function is based solely on the kinematics of the primary joint [79]. This assumes the kinematics at secondary proximal or distal joints have a negligible effect and ignores any effect of biarticular muscles [110], which have been shown in muscle models to influence performance [95]. Developing this method further, Lewis et al. developed a biarticular representation of maximal voluntary ankle plantar flexor torque (primary joint: ankle; secondary joint: knee) [113]. This was reported to be a more accurate representation than an existing single-joint function, with weighted root mean square differences against a measured maximum torque of 3\% rather than 19\% [113]. The authors concluded that a biarticular representation of ankle plantar flexor torque is necessary for torque-driven simulation models where the knee is flexed by more than $40^{\circ}$. Similarly, knee flexor and extensor torques expressed as a function of kinematics at both the knee (primary joint) and hip (secondary joint) were more accurate than a monoarticular function at secondary hip angles other than that used during knee monoarticular dynamometer measurements [114]. Monoarticular torque actuators at the hip may overestimate maximal flexion torque and underestimate maximal extension torque with the knee extended, compared to biarticular representations [115].

An alternative approach to determining contractile and series elastic component parameters have been via optimization during the model evaluation phase [11]. For example, the isometric strength parameter within a surrogate torque profile from an elite male gymnast was varied to match two recorded performances by a different athlete in the takeoff phase of springboard diving [11]. This approach assumed maximum activation during the recorded performances, and so prevented greater activation in subsequent 
optimizations. Due to limitations in the accuracy of strength parameters, this approach should be reserved for situations where individual-specific strength measurements are not feasible.

Despite the advantages of torque-driven models, this approach mostly $[116,117]$ restricts individual-specific forward-dynamics simulation models to two-dimensions. At present, a technique for determining and describing individual-specific maximal torque profiles at joints such as the hip and shoulder collectively about three axes (e.g., flexionextension, abduction-adduction, internal-external rotation) has not been established. The advantage of torque-driven models over muscle-driven models- that individual-specific maximal strength parameters can be determined in vivo-is therefore only true for twodimensional representations. This has resulted in a divided approach to methodological advancement in the simulation modeling community: incorporating effects of nonplanar movements by increasing the complexity of torque-driven models [118]; or improving the individual-specificity of parameters within muscle-driven models [100-102,119].

\section{Range of Motion Constraints}

To prevent joint angles exceeding anatomical limits, passive restorative torques have commonly been applied at the extremes of the range of motion $[10,13,120,121]$. The specific approach used has included passive elastic joint moments via an exponential model [120] in triple-jumping [10]. For passive restorative torques limiting shoulder flexion in the handspring somersault vault, Yeadon et al. fit a similar function [122] to wrist and hip extension isovelocity data [121]. Finally, a viscoelastic spring has been used to incorporate elbow hyperextension in cricket fast bowling, with stiffness and damping parameters determined via an optimization algorithm to match recorded performances $[13,123]$. Scaling parameters during model evaluation may be the most appropriate way to attempt parameter individualization, given the potentially injurious nature of experimentally recording passive elastic restorative torques. Nonetheless, range of motion constraints must be incorporated to avoid unrealistic optimal movement solutions. Methods in which restorative constraints ramp up (rather than employing hard limits) allow integration continuity within the iterative methods used to run the simulation models [124].

\subsubsection{Functional Constraints}

Muscle Activation Constraints

In forward-dynamics simulation models, time-dependent constraints are required to mimic the role of the action potential and regulate the activation of each muscle or torque generator incorporated within the system. Typically, a time-dependent function is employed where activation varies on a scale from 0 (no activation) to 1 (maximal activation). This function is multiplied by the maximum voluntary muscle force (muscle-driven) or joint torque (torque-driven) available at each time point, based on the kinematic joint conditions, to determine the force or torque exerted. Movements within forward-dynamics simulation models are initiated and controlled via parameters within a function governing the activation profile of each muscle or torque actuator. This enables activation timings to be varied within realistic bounds (e.g., guided by literature or electromyography) to optimize performance within individual-specific strength capabilities [4].

While a simple "bang-bang" or "on-off" approach to activation profiles has been adopted [95,125-127], instantaneous changes in activation result in unrealistically fast rates of force development. This is a limitation as the optimal performance of sporting movements has been shown to be sensitive to muscle activation rise times [32,128]. More recently, a ramped activation method has been employed, utilizing and varying a limited number of activation level rise and fall onsets, rates and magnitudes $[9,35,36]$. Future simulation of more complex tasks may require more sophisticated muscle activation constraints than have previously been used. 


\section{Joint Kinematic Constraints}

Where strength is not a limiting factor in a movement, joint angle time histories have sometimes been used as drivers for forward-dynamics simulation models, with the resulting motion specified by the whole-body mass center and orientation kinematics. Examples include aerial phases of high jumping [129], trampolining [37], and diving [130]. Where strength may influence performance, constraints have occasionally limited joint torques within angle-driven models to prevent unrealistic movements [58,131]. In instances where this approach is deemed suitable, angle-driven models benefit from the ease of control and superior computational speed compared with muscle-driven or torque-driven approaches, as well as potentially avoiding the need for realistic individual-specific strength parameters.

Joint-angle time histories have also been used to drive specific joints within mostly torque-driven forward-dynamics simulation models of maximal effort sporting movements, particularly where actuator strength is not a limiting factor and the kinematics at the joint are considered to have a negligible effect on model outcomes $[10,13]$. While it is possible to manipulate the joint angle-time histories within optimization procedures, this is not recommended as the joint angles, and associated torques within any optimized solution may not be feasible [13].

\section{Planar Constraints}

An obvious limitation of planar approaches is the introduction of errors due to any out-of-plane movement. A common assumption of planar simulation models is that the bilateral hip and shoulder joint centers are coincident (i.e., left and right joints share a common joint center in the plane of the model). While this assumption reduces the number of linked segments required, it fails to incorporate non-sagittal plane rotations of the pelvis and torso. Any such rotations would cause the hip and shoulder joint center projections to become non-coincident in the sagittal plane [118]. While this approach has been deemed acceptable for models of running and jumping [60,66,68,126,132], it has limited the accuracy of the predicted ground reaction forces and distal end-point kinematics in cricket fast bowling [118]. Felton et al. overcame this, enabling non-coincident hip and shoulder joint centers by driving the length and orientation of massless pelvis and shoulder segments (connecting the right and left joint centers) using experimentally recorded time histories [118]. To incorporate lateral side-flexion, the length of the torso plus head segment was also driven using experimentally recorded individual-specific time histories while adjusting segmental inertia parameters for the change in length [133]. This novel solution allows some out of plane rotations to be modeled within a largely planar simulation model, avoiding the need for experimentally challenging estimation of three-dimensional individual-specific strength constraints [34].

\subsection{Environmental Constraints}

\section{Constrained Interactions with External Surfaces}

The simplest method for modeling interactions between body segments and external surfaces such as the ground or sports equipment has been a hinge joint, enabling rotational but not translational movement [134]. However, this method cannot facilitate the nonzero initial velocity of an impact with an external surface. While a hinge joint may be appropriate for a stationary foot-ground contact or hand-held object, alternative solutions are required for more complex interactions involving translation between segment and external surface.

The most common solution to represent interactions with external surfaces in forwarddynamics simulation models has been to generate ground reaction forces via viscoelastic springs at a finite number of locations. This approach has been used to model specific elastic structures, including the heel pad [69], foot-tumble track interface [8], and handhigh bar interface [15], as well as general foot-shoe-ground interfaces $[10,13,66]$. The constraint complexity has ranged from damped linear springs [8] to highly nonlinear equations [135], and from less than three contact points [35,66] to as many as 66 during heel-toe running [135]. To ensure the horizontal ground reaction force decays to zero at 
the same time as the vertical force, viscoelastic spring horizontal force functions have been expressed as a function of the same spring's vertical force [66].

As an alternative to viscoelastic springs, a frictional solution also has been used to generate horizontal ground reaction forces. Within this approach, the horizontal force is defined as a function of the vertical force and the horizontal velocity of the contact point [136]. Dynamic and static friction has been combined in a model of handspring straight somersault vaulting in gymnastics, with the transition between models at a specified tangential velocity [137]. This combined method was adopted to replicate the visually observed sliding of hands across the vault surface prior to static friction. The two-state approach was compared to more complex pseudo-Coulomb friction, reporting similar results as well as faster simulation and optimization times.

Since it is not always feasible to measure the viscoelastic or frictional coefficients for each point of contact with an external surface, the parameters are often determined using a similar process to that for wobbling mass viscoelastic parameters (with all viscoelastic parameters often determined simultaneously). The model is driven using experimentally recorded kinematics, with the unknown parameters varied within set bounds by an optimization algorithm to minimize kinetic and whole-body kinematic differences between simulated and experimental performances [66]. The magnitude of compliance permitted is restricted using penalties within the optimization process cost function. While maximum deformations of $11.5 \mathrm{~mm}$ and $12.7 \mathrm{~mm}$ have been reported experimentally at the shoe sole and human heel pad, respectively [138], simulation viscoelastic foot-ground interfaces have been allowed up to $56 \mathrm{~mm}$ of compliance, not only at the heel but also at the toe and metatarsophalangeal joint [60]. This increased compliance likely compensates for the lack of compliance elsewhere in the body, such as within the medial longitudinal foot arch $[139,140]$, joint structures [61,62], or vertebra [141]. The effects of foot-ground compliance limits on the ability of a whole-body forward-dynamics simulation model of triple jumping to match experimentally recorded performances and ground reaction forces were previously investigated [60]. It was concluded that an unrestricted model is appropriate for simulating kinematic performance, but compliance is required elsewhere in the link system (e.g., within joint structures) to accurately calculate internal forces. This may also improve the timing of modeled elastic wave transmission [60], which is typically instantaneous in rigid systems, but not in vivo [142].

\subsection{Task Constraints}

Application of forward-dynamics simulation models to predict individual-specific optimum technique has been mostly limited to "closed" skills, where environmental and task constraints remain relatively constant $[1,143]$. Constraints relating to the task being represented by the forward-dynamics simulation model are often incorporated using penalty functions within optimization algorithms [10,12,21,110,129]. Importantly, penalty functions should ramp-up, rather than utilizing "all or nothing" penalties, increasing the likelihood of optimization algorithms converging to global maxima or minima (depending on the cost function), which must not incur any penalties. Examples have included linear, exponential, and logarithmic ramped penalty functions. Task constraints often involve the ability to perform subsequent movements, which may or may not be simulated. This has included kinematics linked to the ability to regrasp the bar in gymnastics [129], landing orientation for a subsequent phase of the triple jump [10,21], board clearance in diving [12], and bar clearance in high jump [110]. Constraints representing the sporting laws of the movement have also been included, such as ensuring the elbow in cricket bowling does not extend by more than 15 degrees between the instant of a horizontal upper arm and ball release $[13,109]$. Secondary performance outcomes have also been constrained within acceptable limits while optimizing for primary outcomes (e.g., constraining ball landing location while optimizing for ball release speed) [13,109]. 


\subsection{Self-Organization Processes}

The application of self-organization processes within forward-dynamics simulation models of maximal effort sporting movements has been limited. This has predominately been due to difficulty in measuring and establishing realistic mathematical constraints. One such process, "intrinsic dynamics", describes the preferred nodes of coordination or coordination tendencies that exist (often spontaneously or as a result of its previous activity) in a movement system at the onset of learning [144]. Although these attractors have been observed in bimanual coordination tasks [145-147], the greater degrees of freedom in sporting movements makes this methodologically challenging [1], and the incorporation of such pre-existing information within simulation models presents a further challenge. The greatest influence of intrinsic dynamics may be in determining the likelihood of an individual adopting and reliably reproducing any theoretical optimum movement solution [1]. This may be dependent upon both the stability of the attractor corresponding to the individual's current technique and its proximity within the dynamic attractor landscape to that corresponding to the theoretical optimum technique $[1,2,22,147,148]$.

One related factor which has been incorporated into forward-dynamics simulation representations of optimum performance, albeit without the incorporation of intrinsic dynamics, is the stability of the predicted movement pattern. Given that inherent intraindividual variability in movement and activation patterns prevents recurrence of the same exact movement, the optimal movement pattern predicted by a forward-dynamics simulation model should be robust to perturbations [149] and not simply a single greatest one-off performance. Recognizing this, Hiley and Yeadon manipulated the quintic splines used to angle-drive their simulation of the upstart on even bars [150]. Each simulation within their optimization was repeated 1000 times with turning points of the angle-time histories varied according to experimentally recorded intraindividual variation [151]. The movement solution deemed optimal was the one which maximized success within this noisy environment. A similar approach has subsequently been used to quantify the margin for error in movement timing [152,153], as well as the effect of constraints such as strength and variability on margin for error [154]. Applying this approach to muscle or torque actuator activation timings could enable inherent movement variability to be included within the optimization process of muscle-driven and torque-driven forward-dynamics simulation models of maximum effort sporting movements [124].

\section{Review of Model Evaluation}

A limitation of many simulation models is an unknown degree of accuracy in model outputs $[3,155]$. Before any simulation model can be used to answer research questions and infer conclusions, it is necessary to evaluate the model $[3,9,30,155]$. Evaluation against experimental performance data given the same initial conditions can ensure that the model is a sufficiently accurate representation of the activity and mechanical system being modeled $[9,35,60,118]$. Researchers should be aware that this only confirms that the model can generate a movement pattern to recreate the recorded performance and does not guarantee that any subsequently optimized movement solution is possible by the individual [30].

Model outputs have been evaluated against real performances (by the same individual being modeled) using optimization algorithms to minimize a score or cost function, often a weighted mean of differences (e.g., kinetic and kinematic parameters that the model should match) [4]. This process enables quantification of errors and/or the effects of any inherent assumptions, both of which must be considered when analyzing model outputs to inform future research, scientific knowledge, or applied practice. Forward-dynamics simulation models have been considered satisfactory representations of the modeled sporting movement when the evaluated simulation score or cost is less than $10 \%[4,9,156]$ or ideally less than $5 \%[10,11,13,35]$. Accepted differences have typically been greater when including kinetics within the cost function compared to when kinematics alone have been considered $[10,60]$. 
When deriving the cost function and a satisfactory magnitude of difference, the intended application of the model should be considered [4]. Just as with statistical inference in experimental sports biomechanics studies [157], all parameters and methodologies used in a theoretical approach should be justified. To ensure the validity of the evaluation process, future researchers may look to pre-register, or at least specify within the study, the cost functions to be used and the criteria required for successful evaluation [158]. This will reduce the possibility for the modeling equivalent of " $p$-hacking" $[159,160]$, where cost functions or criteria are adjusted until "satisfactory" scores are achieved.

Theoretical optimum individual-specific movement solutions and performance outcomes should also be evaluated anecdotally to ensure the performances are within bounds deemed realistic [13]. This process should also seek to prevent extrapolating the model beyond the range of situations in which it has been evaluated and in which accuracy of the model constraints are known [4,30]. For this purpose, it has been suggested to evaluate the model using experimental data from an elite performer capable of producing close to optimal performances [4] and ideally using different experimental trials to the ones any parameters may have been determined from [156].

\section{Review of Model Application}

Post-evaluation, forward-dynamics simulation models of maximal effort sporting movements have been used to investigate alternative techniques $[10,19]$, quantify the contribution of various factors to performance [21], identify performance limiting factors [8,13,124], quantify the sensitivity of performance to various factors or 'rate limiters' [12,18-20], and identify the optimum technique for an individual [12,13]. In addition. they have been applied to facilitate a greater understanding of aspects of motor control contributing to whole-body movement $[18,130,161,162]$. These insights into the mechanics of sports techniques would not be possible from experimental observations.

The research questions above have all been addressed by running multiple simulations with different inputs. To identify an optimum solution for any criteria, an objective function or performance score must first be defined. This function is then maximized or minimized by varying specified model inputs within realistic pre-determined limits using optimization algorithms such as simulated annealing [163] or genetic algorithm [164]. Alternative optimization approaches such as direct collocation optimal control [165-167] have been utilized more frequently in the muscle-driven model literature and may enhance computational speed. If attempting to predict optimum performance, the objective function must represent the task objective of the modeled activity. This has been a simple one-parameter function (e.g., maximizing jump height [124]) or multiple parameter functions (e.g., minimizing joint torque and joint torque change, while maximizing success in the presence of movement variability in the upstart of gymnastics [150]). In the example of this multiple parameter functions in gymnastics, the optimizations based on minimizing joint torques diverged from an elite gymnast's movement, whereas maximizing success given inherent movement variability generated a solution close to the gymnast's movement [150]. This highlights the need for researchers to consider the true nature of task objectives when defining optimization criteria. It is likely any true optimum technique for an individual is dependent on a combination of factors, including spatial and temporal accuracy considerations, robustness to variation from internal or external sources, and musculoskeletal loading, and so these factors should be considered in future optimization cost functions.

\section{Discussion}

Since 1987 when Baumann argued that "if biomechanics is not capable of incorporating more of the essential anatomical and neurophysiological characteristics of the human body, then it does not deserve its prefix 'bio' and it will not arrive at its real goals" [168] (p. 57), the representation of organismic, environmental, and task constraints within forward-dynamics simulation models has substantially increased in complexity. Due to 
technological advances, not only is it much easier to collect accurate and individual-specific data, improvements in computational processing power enable far more complex representations to be incorporated within dynamical systems. This has primarily led to the development of organismic anatomical and strength constraints, as well as environmental constraints governing interactions between the body and external objects. The incorporation of task constraints has remained relatively unchanged, with ramped penalty functions preferred to an "all or nothing" approach. Although neurophysiological constraints regarding muscle activation and voluntary rather than tetanic force representations have been developed, the incorporation of self-organizational processes representing movement variability and intrinsic dynamics remains limited.

Modeled anatomical constraints have improved from representations of the body as a system of pin joint linked rigid segments $[14,35]$ to incorporating wobbling masses connected using nonlinear viscoelastic springs $[10,13,64]$. This has increased the ability of forward-dynamics simulation models to recreate experimental ground reaction forces and responses to impacts [63,64], albeit not entirely [60]. Although this method enables soft tissue displacement, future advancements may facilitate more realistic displacement magnitudes and damping periods $[60,70,71]$. Additionally, the inclusion of compliance within joint structures $[61,62]$ may facilitate more accurate predictions of ground reaction forces, internal forces, and elastic wave transmission in sporting movements with great impact forces [60,142].

Representation of strength constraints within forward-dynamics simulation models has also improved. The development of monoarticular [79], and more recently biarticular [113], functions describing the force-generating capabilities of contractile components, as well as representations of the series elastic component as a linear spring [35], have enabled rotational muscle-tendon complexes to represent the net effect of the muscles at each joint. This has further enabled individual-specific strength parameters to be incorporated within planar forward-dynamics simulation models [79], although difficulties determining accurate and individual-specific strength parameters for three-dimensional models remain. Considerable increases in the potential applications of forward-dynamics models will be achieved through either individual-specific maximal muscle parameters or three-dimensional torque functions for contractile elements at joints with substantial three-dimensional contributes to performance (e.g., hip and shoulder). Until then, planar models are likely to evolve to incorporate effects of nonplanar rotations through the novel application of planar constraints [118].

More minor developments have occurred for the environmental constraints representing interactions with external surfaces. While the use of springs at various contact points has remained fairly constant, the functions governing spring stiffness and damping $[8,66,135]$, as well as realistic compliance constraints [60], have been explored. Improved representation of compliance elsewhere in the system [60] will likely enable more realistic constraints [138] at the foot-ground interface in future simulation models.

The lack of self-organization processes applied within forward-dynamics simulation models is a cause of discussion regarding their efficacy to predict individual-specific optimal technique [1]. While effects of movement variability have been investigated [150], their incorporation within torque-driven simulation models has been sporadic. This process should be utilized in future torque-driven models since individuals do not reproduce identical movement patterns for a repetitive task [149], and so predicted optimal movement patterns must be robust to perturbations in activation timings. The optimum movement solution must therefore be the one that maximizes success within a noisy environment. Capturing and representing the intrinsic dynamics of preferred coordination nodes $[144,148]$ will be more challenging. These tendencies are shaped by multiple factors, including previous experiences and environmental influences, which are currently extremely difficult to measure and incorporate within forward-dynamics simulation models [1]. This remains the main limitation of individual-specific optimal technique predictions from a dynamical systems theory perspective [1]. If an accurate method of measuring and representing these 
processes is found and determined to permanently limit the availability or efficacy of potential movement patterns of an individual, then this should be incorporated within future forward-dynamics simulation models where possible.

Forward-dynamics simulation models have been considered useful as an investigatory tool to observe cause and effect relationships, where the effect of manipulating one variable can be determined while controlling all others [1]. The cause and effect relationships determined can be used to understand potential factors generally limiting performance in a hypothetical individual. This is preferable to "in general" observations derived experimentally from a group of individuals since cause and effect can be confidently inferred, and the potential for interindividual relationships that do not reflect intraindividual relationships is avoided [3]. Compared to this approach, using forward-dynamics simulations to predict individual-specific optimal techniques for maximal effort sporting movements has created more controversy. The failure to incorporate representations of the attractor landscape and suitable self-organization processes has led dynamical system theorists to suggest that it may not be possible for individuals to obtain their predicted optimum technique [1]. The magnitude of errors introduced by this limitation cannot be quantified and evaluated since a direct comparison to a "true" optimum performance is not possible, and the various factors limiting individual-specific performance cannot currently be isolated experimentally. Only predicting the optimal technique for an individual such as a world record holder with a technique considered close to optimal may come close [4], and even then, the evaluation results could not be extrapolated to other models of sub-elite athletes. Forward-dynamics simulation models are unlikely to ever provide a perfect prediction of optimal technique since they are simplified representations of the human body and are always likely to incorporate various sources of systematic error. The overall magnitude of the optimal performance outcome measure should, therefore, clearly be treated with caution and assessed as part of the iterative model evaluation process [13].

Individual-specific forward-dynamics simulation models of maximum effort sporting movements have been developed by simplifying the human body mechanical system as much as possible while maintaining sufficient complexity to address the research question $[14,34]$. Although an identical replication of the human body would be ideal from a dynamical systems perspective, models are by definition simplifications of the systems they represent. This has therefore facilitated debate regarding the complexity required to suitably model the constraints [23] and self-organizational processes of the human body [22] necessary to identify individual-specific optimal technique of maximal effort sporting movements [1]. While this debate can advance the forward-dynamics simulation modeling methodology, it should be noted that the hypothetical potential of an individual athlete to actually achieve their predicted optimal performance provides only an anecdotal assessment of simulation model efficacy. Indeed, direct quantitative comparison of predicted vs. actual optimum technique is not possible since the purpose of forward-dynamics simulation model optimization is often precisely to predict this unknown and unmeasurable performance. Where the proposed application is to predict individual-specific optimum techniques, simulation modeling researchers should therefore continue to consider concerns resulting from dynamical systems theory regarding the complexity of models and particularly regarding self-organization processes.

The limited range of predominantly planar sporting movements that have been successfully simulated is often used as evidence for the difficulty of producing a representative set of organismic, environmental and task constraints [1]. While the successful representation of constraints within complex movements is certainly challenging, the results of existing forward-dynamics simulation models should not be questioned solely on the basis of the limited number of successful examples in applied sports biomechanics [2]. With future developments enabling more complex constraints and self-organizational processes to be employed, it is possible that approaches currently only successful in relatively simple movements could be expanded to more complex sporting movements. 
In the future, successfully evaluated forward-dynamics simulation models estimating individual-specific optimal techniques of sporting movements may be used as indicative rather than predictive tools within a coaching framework to aid applied practice and understanding $[169,170]$. The traditional coaching framework for analyzing and prescribing changes in technique tends to develop primarily via anecdotal evidence from experiential knowledge or other coaches, as well as scientific knowledge from group-based experimental research results [169,171-173]. The knowledge and understanding used to inform decisions can be enhanced via forward-dynamics simulation models' more detailed consideration of individual constraints and processes such as robustness to perturbations. Applying forward-dynamics simulation models within applied coaching, therefore, has the benefit of helping to inform and reduce the ongoing predictions expected of coaches [170], although coaches and individuals should be encouraged to set realistic expectations [174]. The "optimal" technique and performance outcome should not currently be viewed as a definitively achievable target against which an individual is judged. This may not be strictly possible to achieve due to potential self-organizational and other constraints. Rather, as with current coaching processes, the individual should work towards achieving the broadly indicated and mechanically justified differences in relation to their current technique (e.g., in one recent individual-specific example: more extended front ankle and knee joint angles; increased trunk flexion; a longer delay in the onset of arm circumduction [13]). Coaching practices necessary to facilitate any alteration in (or search for) technique or coordinative structures should be explored outside of the simulation literature $[175,176]$. The debate between dynamical systems theorists and sports biomechanists who construct and evaluate forward-dynamics simulation models will continue over the accuracy of individual-specific optimal techniques and the individual's ability to achieve them while comparison to a true optimum remains impossible. Nonetheless, critical evaluation of the constraints and processes currently employed should inform best practice and future research directions within the field.

\section{Conclusions}

This review has critically evaluated forward-dynamics simulation models of maximal effort sporting movements using a dynamical systems theory framework. Each study typically follows a four-stage process of model construction, parameter determination, model evaluation, and model optimization. This review has presented a number of considerations for future researchers at each of these stages. The representation of organismic, environmental, and task constraints has substantially increased in complexity over recent years. However, the incorporation of self-organizational processes representing movement variability and "intrinsic dynamics" remains limited. Researchers should continue to consider concerns resulting from dynamical systems theory regarding the complexity of models. In particular, the relevance and application of self-organizational processes should be explored within forward-dynamics simulation models to predict individual-specific optimal techniques. Applying this theoretical approach within coaching has the potential to be an indicative tool to identify broad mechanically justified differences in relation to an individual's current technique, provided the assumptions and limitations within this review are considered.

Author Contributions: Conceptualization, all authors; writing—original draft preparation, S.A.M.-N and P.J.F; writing — review and editing, all authors; supervision, M.A.K. All authors have read and agreed to the published version of the manuscript.

Funding: This research received no external funding.

Institutional Review Board Statement: Not applicable.

Informed Consent Statement: Not applicable.

Data Availability Statement: Not applicable.

Conflicts of Interest: The authors declare no conflict of interest. 


\section{References}

1. Glazier, P.S.; Mehdizadeh, S. In search of sports biomechanics' holy grail: Can athlete-specific optimum sports techniques be identified? J. Biomech. 2019, 94, 1-4. [CrossRef]

2. Glazier, P.S.; Mehdizadeh, S. Challenging conventional paradigms in applied sports biomechanics research. Sport. Med. 2019, 49, 171-176. [CrossRef]

3. Yeadon, M.R.; Challis, J.H. The future of performance-related sports biomechanics research. J. Sports Sci. 1994, 12, 3-32. [CrossRef]

4. Yeadon, M.R.; King, M.A. Biomechanical simulation models of sports activities. In Handbook of Biomechanics and Human Movement Science; Hong, Y., Bartlett, R.M., Eds.; Routledge: Oxford, UK, 2008; pp. 367-379.

5. Fisher, A.J.; Medaglia, J.D.; Jeronimus, B.F. Lack of group-to-individual generalizability is a threat to human subjects research. Proc. Natl. Acad. Sci. USA 2018, 115, E6106-E6115. [CrossRef]

6. Sprigings, E.J. Sport biomechanics: Data collection, modelling, and implementation stages of development. Can. J. Sport Sci. 1988, 13, 3-7.

7. Irwin, G.; Bezodis, I.; Kerwin, D. Biomechanics for coaches. In An Introduction to Sports Coaching: Connecting Theory and Practice; Jones, R.L., Kingston, K., Eds.; Routledge: London, UK, 2013; pp. 145-160.

8. King, M.A.; Yeadon, M.R. Maximising somersault rotation in tumbling. J. Biomech. 2004, 37, 471-477. [CrossRef]

9. King, M.A.; Wilson, C.; Yeadon, M.R. Evaluation of a torque-driven model of jumping for height. J. Appl. Biomech. 2006, 22, 264-274. [CrossRef]

10. Allen, S.J.; King, M.A.; Yeadon, M.R. Is a single or double arm technique more advantageous in triple jumping? J. Biomech. 2010, 43, 3156-3161. [CrossRef]

11. King, M.A.; Kong, P.W.; Yeadon, M.R. Determining effective subject-specific strength levels for forward dives using computer simulations of recorded performances. J. Biomech. 2009, 42, 2672-2677. [CrossRef]

12. King, M.A.; Kong, P.W.; Yeadon, M.R. Maximising forward somersault rotation in springboard diving. J. Biomech. 2019, 85, 157-163. [CrossRef]

13. Felton, P.J.; Yeadon, M.R.; King, M.A. Optimising the front foot contact phase of the cricket fast bowling action. J. Sports Sci. 2020, 38, 2054-2062. [CrossRef]

14. Alexander, R.M. Optimum take-off techniques for high and long jumps. Philos. Trans. R. Soc. Lond. Ser. B Biol. Sci. 1990, 329, 3-10. [CrossRef]

15. Hiley, M.J.; Yeadon, M.R. The margin for error when releasing the high bar for dismounts. J. Biomech. 2003, 36, 313-319. [CrossRef]

16. Kane, T.R.; Levinson, D.A. Dynamics, Theory and Applications; McGraw Hill: New York, NY, USA, 1985; ISBN 0-07-037846-0.

17. Press, W.H.; Flannery, B.P.; Teukolsky, S.A.; Vetterling, W. Numerical Recipes: The Art of Scientific Computing; Cambridge University Press: Cambridge, UK, 1988.

18. King, M.A.; Yeadon, M.R. Coping with perturbations to a layout somersault in tumbling. J. Biomech. 2003, 36, 921-927. [CrossRef]

19. Allen, S.J.; King, M.A.; Yeadon, M.R. Optimisation of phase ratio in the triple jump using computer simulation. Hum. Mov. Sci. 2016, 46, 167-176. [CrossRef] [PubMed]

20. Allen, S.J.; Yeadon, M.R.; King, M.A. The effect of increasing strength and approach velocity on triple jump performance. J. Biomech. 2016, 49, 3796-3802. [CrossRef]

21. Allen, S.J.; King, M.A.; Yeadon, M.R. Trade-offs between horizontal and vertical velocities during triple jumping and the effect on phase distances. J. Biomech. 2013, 46, 979-983. [CrossRef]

22. Kelso, J.A.S. Dynamic Patterns: The Self-Organization of Brain and Behavior; MIT Press: Cambridge, MA, USA, 1995.

23. Newell, K.M. Constraints on the development of coordination. In Motor Development in Children: Aspects of Coordination and Control; Wade, M., Whiting, H.T.A., Eds.; Martinus Nijhoff: Dordrecht, The Netherlands, 1986; pp. 341-360.

24. Camazine, S.; Deneubourg, J.L.; Franks, N.R.; Sneyd, J.; Bonabeau, E.; Theraula, G. Self-Organization in Biological Systems; Princeton University Press: Princeton, NJ, USA, 2001.

25. Glazier, P.S.; Robins, M.T. Self-organisation and constraints in sports performance. In Routledge Handbook of Sports Performance Analysis; McGarry, T., O'Donoghue, P., Sampaio, J., Eds.; Routledge: London, UK, 2013; pp. $42-51$.

26. Newell, K.M.; Jordan, K. Task constraints and movement organization: A common language. In Ecological Task Analysis and Movement; Davis, W.E., Broadhead, G.D., Eds.; Human Kinetics: Champaign, IL, USA, 2007; pp. 5-23.

27. Glazier, P.S. Towards a Grand Unified Theory of sports performance. Hum. Mov. Sci. 2017, 56, 139-156. [CrossRef]

28. McGinnis, P.M.; Newell, K.M. Topological dynamics: A framework for describing movement and its constraints. Hum. Mov. Sci. 1982, 1, 289-305. [CrossRef]

29. Kugler, P.N.; Scott Kelso, J.A.; Turvey, M.T. 1 On the concept of coordinative structures as dissipative structures: I. Theoretical lines of convergence. Adv. Psychol. 1980, 1, 3-47. [CrossRef]

30. Panjabi, M. Validation of mathematical models. J. Biomech. 1979, 12, 238. [CrossRef]

31. Pandy, M.G. Simple and complex models for studying muscle function in walking. Philos. Trans. R. Soc. London Ser. B Biol. Sci. 2003, 358, 1501-1509. [CrossRef]

32. Anderson, F.C.; Pandy, M.G. A dynamic optimization solution for vertical jumping in three dimensions. Comput. Methods Biomech. Biomed. Eng. 1999, 2, 201-231. [CrossRef]

33. Hatze, H. A comprehensive model for human motion simulation and its application to the take-off phase of the long jump. J. Biomech. 1981, 14, 135-142. [CrossRef] 
34. Yeadon, M.R.; King, M.A. Computer simulation modelling in sport. In Biomechanical Evaluation of Movement in Sport and Exercise: BASES Guidelines; Payton, C.J., Bartlett, R.M., Eds.; Routledge: London, UK, 2018; pp. 176-205.

35. Yeadon, M.R.; King, M.A. Evaluation of a torque-driven simulation model of tumbling. J. Appl. Biomech. 2002, 18, 195-206. [CrossRef]

36. Yeadon, M.R.; King, M.A.; Forrester, S.E.; Caldwell, G.E.; Pain, M.T.G. The need for muscle co-contraction prior to a landing. J. Biomech. 2010, 43, 364-369. [CrossRef]

37. Yeadon, M.R.; Atha, J.; Hales, F.D. The simulation of aerial movement-IV. A computer simulation model. J. Biomech. 1990, 23, 85-89. [CrossRef]

38. Rajagopal, A.; Dembia, C.L.; DeMers, M.S.; Delp, D.D.; Hicks, J.L.; Delp, S.L. Full-body musculoskeletal model for muscle-driven simulation of human gait. IEEE Trans. Biomed. Eng. 2016, 63, 2068-2079. [CrossRef] [PubMed]

39. Shao, Q.; Bassett, D.N.; Manal, K.; Buchanan, T.S. An EMG-driven model to estimate muscle forces and joint moments in stroke patients. Comput. Biol. Med. 2009, 39, 1083-1088. [CrossRef] [PubMed]

40. Dao, T.T. Rigid musculoskeletal models of the human body ststems: A review. J. Musculoskelet. Res. 2016, 19, 1630001. [CrossRef]

41. Delp, S.L.; Anderson, F.C.; Arnold, A.S.; Loan, P.; Habib, A.; John, C.T.; Guendelman, E.; Thelen, D.G. OpenSim: Open-source software to create and analyze dynamic simulations of movement. IEEE Trans. Biomed. Eng. 2007, 54, 1940-1950. [CrossRef]

42. Reinbolt, J.A.; Seth, A.; Delp, S.L. Simulation of human movement: Applications using OpenSim. Procedia IUTAM 2011, 2, 186-198. [CrossRef]

43. Hinrichs, R.N. Regression equations to predict segmental moments of inertia from anthropometric measurements: An extension of the data of Chandler et al. (1975). J. Biomech. 1985, 18, 621-624. [CrossRef]

44. Chandler, R.F.; Clauser, C.E.; McConville, J.T.; Reynolds, H.M.; Young, J.W. Investigation of inertial properties of the human body. Natl. Highw. Traffic Saf. Adm. 1975, 1-169.

45. Challis, J.H.; Kerwin, D.G. Calculating upper limb inertial parameters. J. Sports Sci. 1992, 10, 275-284. [CrossRef] [PubMed]

46. Hatze, H. A mathematical model for the computational determination of parameter values of anthropomorphic segments. J. Biomech. 1980, 13, 833-843. [CrossRef]

47. Yeadon, M.R. The simulation of aerial movement-II. A mathematical inertia model of the human body. J. Biomech. 1990, 23, 67-74. [CrossRef]

48. Hanavan, E.P. A mathematical model of the human body. Aerosp. Med. Res. Lab. 1964, 1-149.

49. Lewis, A.R.; Robertson, W.S.P.; Phillips, E.J.; Grimshaw, P.N.; Portus, M. The effects of personalized versus generic scaling of body segment masses on joint torques during stationary wheelchair racing. J. Biomech. Eng. 2019, 141, 101001. [CrossRef]

50. Rossi, M.; Lyttle, A.; El-Sallam, A.; Benjanuvatra, N.; Blanksby, B. Body segment inertial parameters of elite swimmers using DXA and indirect methods. J. Sport. Sci. Med. 2013, 12, 761-775.

51. Merrill, Z.; Perera, S.; Cham, R. Predictive regression modeling of body segment parameters using individual-based anthropometric measurements. J. Biomech. 2019, 96, 109349. [CrossRef]

52. Holmes, J.D.; Andrews, D.M.; Durkin, J.L.; Dowling, J.J. Predicting in vivo soft tissue masses of the lower extremity using segment anthropometric measures and DXA. J. Appl. Biomech. 2005, 21, 371-382. [CrossRef]

53. Winter, S.L.; Forrest, S.M.; Wallace, J.; Challis, J.H. A dual X-ray absorptiometry validated geometric model for the calculation of body segment inertial parameters of young females. J. Appl. Biomech. 2018, 34, 89-95. [CrossRef] [PubMed]

54. Wicke, J.; Dumas, G.A.; Costigan, P.A. A comparison between a new model and current models for estimating trunk segment inertial parameters. J. Biomech. 2009, 42, 55-60. [CrossRef]

55. Durkin, J.L.; Dowling, J.J. Body segment parameter estimation of the human lower leg using an elliptical model with validation from DEXA. Ann. Biomed. Eng. 2006, 34, 1483-1493. [CrossRef]

56. Durkin, J.L.; Dowling, J.J.; Scholtes, L. Using mass distribution information to model the human thigh for body segment parameter estimation. J. Biomech. Eng. 2005, 127, 455-464. [CrossRef]

57. Durkin, J.L.; Dowling, J.J. Analysis of body segment parameter differences between four human populations and the estimation errors of four popular mathematical models. J. Biomech. Eng. 2003, 125, 515-522. [CrossRef] [PubMed]

58. Yeadon, M.R.; Hiley, M.J. The mechanics of the backward giant circle on the high bar. Hum. Mov. Sci. 2000, 19, 153-173. [CrossRef]

59. van der Helm, F.C.T. Analysis of the kinematic and dynamic behavior of the shoulder mechanism. J. Biomech. 1994, 27, 527-550. [CrossRef]

60. Allen, S.J.; King, M.A.; Yeadon, M.R. Models incorporating pin joints are suitable for simulating performance but unsuitable for simulating internal loading. J. Biomech. 2012, 45, 1430-1436. [CrossRef]

61. Fragomen, A.T.; McCoy, T.H.; Meyers, K.N.; Rozbruch, S.R. Minimum distraction gap: How much ankle joint space is enough in ankle distraction arthroplasty? HSS J. 2014, 10, 6-12. [CrossRef]

62. Hoshino, A.; Wallace, W.A. Impact-absorbing properties of the human knee. J. Bone Joint Surg. Br. 1987, 69, 807-811. [CrossRef]

63. Gruber, K.; Ruder, H.; Denoth, J.; Schneider, K. A comparative study of impact dynamics: Wobbling mass model versus rigid body models. J. Biomech. 1998, 31, 439-444. [CrossRef]

64. Pain, M.T.G.; Challis, J.H. The influence of soft tissue movement on ground reaction forces, joint torques and joint reaction forces in drop landings. J. Biomech. 2006, 39, 119-124. [CrossRef]

65. Clarys, J.P.; Marfell-Jones, M.J. Anthropometric prediction of component tissue masses in the minor limb segments of the human body. Hum. Biol. 1986, 58, 761-769. 
66. Wilson, C.; King, M.A.; Yeadon, M.R. Determination of subject-specific model parameters for visco-elastic elements. J. Biomech. 2006, 39, 1883-1890. [CrossRef]

67. Clarys, J.P.; Martin, A.D.; Drinkwater, D.T. Gross tissue weights in the human body by cadaver dissection. Hum. Biol. 1984, 56, 459-473.

68. Cole, G.; Nigg, B.; van den Bogert, A.; Gerritsen, K. Lower extremity joint loading during impact in running. Clin. Biomech. 1996, 11, 181-193. [CrossRef]

69. Pain, M.T.G.; Challis, J.H. The role of the heel pad and shank soft tissue during impacts: A further resolution of a paradox. J. Biomech. 2001, 34, 327-333. [CrossRef]

70. Furlong, L.-A.M.; Voukelatos, D.; Kong, P.W.; Pain, M.T.G. Changes in inertial parameters of the lower limb during the impact phase of dynamic tasks. J. Biomech. 2020, 99, 109488. [CrossRef]

71. Minetti, A.E.; Belli, G. A model for the estimation of visceral mass displacement in periodic movements. J. Biomech. 1994, 27, 97-101. [CrossRef]

72. von Tscharner, V. Intensity analysis in time-frequency space of surface myoelectric signals by wavelets of specified resolution. $J$. Electromyogr. Kinesiol. 2000, 10, 433-445. [CrossRef]

73. Wakeling, J.M.; Nigg, B.M. Modification of soft tissue vibrations in the leg by muscular activity. J. Appl. Physiol. 2001, 90, 412-420. [CrossRef]

74. Pain, M.T.G.; Challis, J.H. Soft tissue motion during impacts: Their potential contributions to energy dissipation. J. Appl. Biomech. 2002, 18, 231-242. [CrossRef]

75. Gasser, H.S.; Hill, A.V. The dynamics of muscular contraction. Proc. R. Soc. Lond. Ser. B Contain. Pap. Biol. Character 1924, 96, 398-437. [CrossRef]

76. Huxley, A.F. Muscle structure and theories of contraction. Prog. Biophys. Biophys. Chem. 1957, 7, 255-318. [CrossRef]

77. Selbie, W.S.; Caldwell, G.E. A simulation study of vertical jumping from different starting postures. J. Biomech. 1996, 29, 1137-1146. [CrossRef]

78. Edman, K.A.P. Contractile performance of skeletal muscle fibres. In Strength and Power in Sport. Vol. III of the Encyclopaedia of Sports Medicine; Komi, P.V., Ed.; Blackwell Scientific: Oxford, UK, 1992.

79. Forrester, S.E.; Yeadon, M.R.; King, M.A.; Pain, M.T.G. Comparing different approaches for determining joint torque parameters from isovelocity dynamometer measurements. J. Biomech. 2011, 44, 955-961. [CrossRef]

80. Gordon, A.M.; Huxley, A.F.; Julian, F.J. The variation in isometric tension with sarcomere length in vertebrate muscle fibres. J. Physiol. 1966, 184, 170-192. [CrossRef]

81. Edman, K.A.; Reggiani, C. The sarcomere length-tension relation determined in short segments of intact muscle fibres of the frog. J. Physiol. 1987, 385, 709-732. [CrossRef]

82. Hill, A.V. The heat of shortening and the dynamic constants of muscle. Proc. R. Soc. London Ser. B Biol. Sci. 1938, 126, 136-195. [CrossRef]

83. Fenn, W.O.; Marsh, B.S. Muscular force at different speeds of shortening. J. Physiol. 1935, 85, 277-297. [CrossRef]

84. Yeadon, M.R.; King, M.A.; Wilson, C. Modelling the maximum voluntary joint torque/angular velocity relationship in human movement. J. Biomech. 2006, 39, 476-482. [CrossRef] [PubMed]

85. Dudley, G.A.; Harris, R.T.; Duvoisin, M.R.; Hather, B.M.; Buchanan, P. Effect of voluntary vs. artificial activation on the relationship of muscle torque to speed. J. Appl. Physiol. 1990, 69, 2215-2221. [CrossRef] [PubMed]

86. Westing, S.H.; Seger, J.Y.; Thorstensson, A. Effects of electrical stimulation on eccentric and concentric torque-velocity relationships during knee extension in man. Acta Physiol. Scand. 1990, 140, 17-22. [CrossRef]

87. Westing, S.H.; Cresswell, A.G.; Thorstensson, A. Muscle activation during maximal voluntary eccentric and concentric knee extension. Eur. J. Appl. Physiol. Occup. Physiol. 1991, 62, 104-108. [CrossRef]

88. Kellis, E.; Baltzopoulos, V. Muscle activation differences between eccentric and concentric isokinetic exercise. Med. Sci. Sport. Exerc. 1998, 30, 1616-1623. [CrossRef] [PubMed]

89. Babault, N.; Pousson, M.; Ballay, Y.; Van Hoecke, J. Activation of human quadriceps femoris during isometric, concentric, and eccentric contractions. J. Appl. Physiol. 2001, 91, 2628-2634. [CrossRef] [PubMed]

90. Pain, M.T.G.; Young, F.; Kim, J.; Forrester, S.E. The torque-velocity relationship in large human muscles: Maximum voluntary versus electrically stimulated behaviour. J. Biomech. 2013, 46, 645-650. [CrossRef]

91. Katz, B. The relation between force and speed in muscular contraction. J. Physiol. 1939, 96, 45-64. [CrossRef]

92. Harry, J.D.; Ward, A.W.; Heglund, N.C.; Morgan, D.L.; McMahon, T.A. Cross-bridge cycling theories cannot explain high-speed lengthening behavior in frog muscle. Biophys. J. 1990, 57, 201-208. [CrossRef]

93. Bobbert, M.F. Dependence of human squat jump performance on the series elastic compliance of the triceps surae: A simulation study. J. Exp. Biol. 2001, 204, 533-542. [PubMed]

94. Winter, D.A. Biomechanics and Motor Control of Human Movement; Wiley: New York, NY, USA, 1990.

95. van Soest, A.J.; Schwab, A.L.; Bobbert, M.F.; van Ingen Schenau, G.J. The influence of the biarticularity of the gastrocnemius muscle on vertical-jumping achievement. J. Biomech. 1993, 26, 1-8. [CrossRef]

96. Böhm, H.; Cole, G.K.; Brüggemann, G.-P.; Ruder, H. Contribution of muscle series elasticity to maximum performance in drop jumping. J. Appl. Biomech. 2006, 22, 3-13. [CrossRef] 
97. Hof, A. In vivo measurement of the series elasticity release curve of human triceps surae muscle. J. Biomech. 1998, 31, 793-800. [CrossRef]

98. Chapman, A.E. The mechanical properties of human muscle. Exerc. Sport Sci. Rev. 1985, 13, 443-501. [CrossRef]

99. Erdemir, A.; McLean, S.; Herzog, W.; van den Bogert, A.J. Model-based estimation of muscle forces exerted during movements. Clin. Biomech. 2007, 22, 131-154. [CrossRef] [PubMed]

100. Lloyd, D.G.; Besier, T.F. An EMG-driven musculoskeletal model to estimate muscle forces and knee joint moments in vivo. J. Biomech. 2003, 36, 765-776. [CrossRef]

101. Winby, C.R.; Lloyd, D.G.; Kirk, T.B. Evaluation of different analytical methods for subject-specific scaling of musculotendon parameters. J. Biomech. 2008, 41, 1682-1688. [CrossRef] [PubMed]

102. Modenese, L.; Ceseracciu, E.; Reggiani, M.; Lloyd, D.G. Estimation of musculotendon parameters for scaled and subject specific musculoskeletal models using an optimization technique. J. Biomech. 2016, 49, 141-148. [CrossRef] [PubMed]

103. Wakeling, J.M.; Tijs, C.; Konow, N.; Biewener, A.A. Modeling muscle function using experimentally determined subject-specific muscle properties. J. Biomech. 2021, 110242. [CrossRef]

104. Bobbert, M.F.; Van Soest, A.J. Effects of muscle strengthening on vertical jump height: A simulation study. Med. Sci. Sports Exerc. 1994, 26, 1012-1020. [CrossRef] [PubMed]

105. Mills, C.; Pain, M.T.G.; Yeadon, M.R. The influence of simulation model complexity on the estimation of internal loading in gymnastics landings. J. Biomech. 2008, 41, 620-628. [CrossRef]

106. Mills, C.; Pain, M.T.G.; Yeadon, M.R. Reducing ground reaction forces in gymnastics' landings may increase internal loading. J. Biomech. 2009, 42, 671-678. [CrossRef] [PubMed]

107. Mills, C.; Yeadon, M.R.; Pain, M.T.G. Modifying landing mat material properties may decrease peak contact forces but increase forefoot forces in gymnastics landings. Sport. Biomech. 2010, 9, 153-164. [CrossRef] [PubMed]

108. Anderson, D.E.; Madigan, M.L.; Nussbaum, M.A. Maximum voluntary joint torque as a function of joint angle and angular velocity: Model development and application to the lower limb. J. Biomech. 2007, 40, 3105-3113. [CrossRef]

109. King, M.A.; Yeadon, M.R. Determining subject-specific torque parameters for use in a torque-driven simulation model of dynamic jumping. J. Appl. Biomech. 2002, 18, 207-217. [CrossRef]

110. Conceição, F.; King, M.A.; Yeadon, M.R.; Lewis, M.G.C.; Forrester, S.E. An isovelocity dynamometer method to determine monoarticular and biarticular muscle parameters. J. Appl. Biomech. 2012, 28, 751-759. [CrossRef] [PubMed]

111. Bobbert, M.F.; van Ingen Schenau, G.J. Isokinetic plantar flexion: Experimental results and model calculations. J. Biomech. 1990, 23, 105-119. [CrossRef]

112. Jacobs, R.; Bobbert, M.F.; van Ingen Schenau, G.J. Mechanical output from individual muscles during explosive leg extensions: The role of biarticular muscles. J. Biomech. 1996, 29, 513-523. [CrossRef]

113. Lewis, M.G.C.; King, M.A.; Yeadon, M.R.; Conceição, F. Are joint torque models limited by an assumption of monoarticularity? J. Appl. Biomech. 2012, 28, 520-529. [CrossRef] [PubMed]

114. King, M.A.; Lewis, M.G.C.; Yeadon, M.R. Is it necessary to include biarticular effects within joint torque representations of knee flexion and knee extension? Int. J. Multiscale Comput. Eng. 2012, 10, 117-130. [CrossRef]

115. Lewis, M.G.C.; Yeadon, M.R.; King, M.A. The effect of accounting for biarticularity in hip flexor and hip extensor joint torque representations. Hum. Mov. Sci. 2018, 57, 388-399. [CrossRef] [PubMed]

116. Febrer-Nafría, M.; Pallarès-López, R.; Fregly, B.J.; Font-Llagunes, J.M. Comparison of different optimal control formulations for generating dynamically consistent crutch walking simulations using a torque-driven model. Mech. Mach. Theory 2020, 154, 104031. [CrossRef]

117. Jiang, Y.; Van Wouwe, T.; De Groote, F.; Liu, C.K. Synthesis of biologically realistic human motion using joint torque actuation. ACM Trans. Graph. 2019, 38, 1-12. [CrossRef]

118. Felton, P.J.; Yeadon, M.R.; King, M.A. Are planar simulation models affected by the assumption of coincident joint centers at the hip and shoulder? J. Appl. Biomech. 2019, 35, 157-163. [CrossRef]

119. Heinen, F.; Sørensen, S.N.; King, M.; Lewis, M.; Lund, M.E.; Rasmussen, J.; de Zee, M. Muscle-tendon unit parameter estimation of a Hill-type musculoskeletal model based on experimentally obtained subject-specific torque profiles. J. Biomech. Eng. 2019, 141, 061005. [CrossRef] [PubMed]

120. Riener, R.; Edrich, T. Identification of passive elastic joint moments in the lower extremities. J. Biomech. 1999, 32, 539-544. [CrossRef]

121. Yeadon, M.R.; Jackson, M.I.; Hiley, M.J. The influence of touchdown conditions and contact phase technique on post-flight height in the straight handspring somersault vault. J. Biomech. 2014, 47, 3143-3148. [CrossRef]

122. Esteki, A.; Mansour, J.M. An experimentally based nonlinear viscoelastic model of joint passive moment. J. Biomech. 1996, 29, 443-450. [CrossRef]

123. Felton, P.J.; King, M.A. The effect of elbow hyperextension on ball speed in cricket fast bowling. J. Sports Sci. 2016, 34, 1752-1758. [CrossRef]

124. Wilson, C.; Yeadon, M.R.; King, M.A. Considerations that affect optimised simulation in a running jump for height. J. Biomech. 2007, 40, 3155-3161. [CrossRef] [PubMed]

125. Levine, W.S.; Zajac, F.E.; Cho, Y.M.; Zomlefer, M.R. The bang-bang phase of maximal height jumps by humans. IFAC Proc. Vol. 1987, 20, 31-36. [CrossRef] 
126. Pandy, M.G.; Zajac, F.E.; Sim, E.; Levine, W.S. An optimal control model for maximum-height human jumping. J. Biomech. 1990, 23, 1185-1198. [CrossRef]

127. Zajac, F.E.; Wicke, R.W.; Levine, W.S. Dependence of jumping performance on muscle properties when humans use only calf muscles for propulsion. J. Biomech. 1984, 17, 513-523. [CrossRef]

128. Bobbert, M.F.; Van Zandwijk, J.P. Dynamics of force and muscle stimulation in human vertical jumping. Med. Sci. Sport. Exerc. 1999, 31, 303-310. [CrossRef]

129. Dapena, J. Simulation of modified human airborne movements. J. Biomech. 1981, 14, 81-89. [CrossRef]

130. Sayyah, M.; Hiley, M.J.; King, M.A.; Yeadon, M.R. Functional variability in the flight phase of one metre springboard forward dives. Hum. Mov. Sci. 2018, 59, 234-243. [CrossRef] [PubMed]

131. Brewin, M.A.; Yeadon, M.R.; Kerwin, D.G. Minimising peak forces at the shoulders during backward longswings on rings. Hum. Mov. Sci. 2000, 19, 717-736. [CrossRef]

132. Ackermann, M.; van den Bogert, A.J. Optimality principles for model-based prediction of human gait. J. Biomech. 2010, 43, 1055-1060. [CrossRef]

133. Hiley, M.J.; Yeadon, M.R.; Buxton, E. Consistency of performances in the Tkatchev release and re-grasp on high bar. Sport. Biomech. 2007, 6, 121-130. [CrossRef] [PubMed]

134. Bobbert, M.F.; Houdijk, H.; de Koning, J.J.; de Groot, G. From a one-legged vertical jump to the speed-skating push-off: A simulation study. J. Appl. Biomech. 2002, 18, 28-45. [CrossRef]

135. Wright, I.C.; Neptune, R.R.; van den Bogert, A.J.; Nigg, B.M. Passive regulation of impact forces in heel-toe running. Clin. Biomech. 1998, 13, 521-531. [CrossRef]

136. Gerritsen, K.G.M.; van den Bogert, A.J.; Nigg, B.M. Direct dynamics simulation of the impact phase in heel-toe running. J. Biomech. 1995, 28, 661-668. [CrossRef]

137. Jackson, M.I.; Hiley, M.J.; Yeadon, M.R. A comparison of Coulomb and pseudo-Coulomb friction implementations: Application to the table contact phase of gymnastics vaulting. J. Biomech. 2011, 44, 2706-2711. [CrossRef] [PubMed]

138. Kinoshita, H.; Ogawa, T.; Kuzuhara, K.; Ikuta, K. In vivo examination of the dynamic properties of the human heel pad. Int. J. Sports Med. 1993, 14, 312-319. [CrossRef]

139. Hageman, E.R.; Hall, M.; Sterner, E.G.; Mirka, G.A. Medial longitudinal arch deformation during walking and stair navigation while carrying loads. Foot Ankle Int. 2011, 32, 623-629. [CrossRef]

140. Nielsen, R.G.; Rathleff, M.S.; Simonsen, O.H.; Langberg, H. Determination of normal values for navicular drop during walking: A new model correcting for foot length and gender. J. Foot Ankle Res. 2009, 2, 12. [CrossRef]

141. Helliwell, P.S.; Smeathers, J.E.; Wright, V. Shock absorption by the spinal column in normals and in ankylosing spondylitis. Proc. Inst. Mech. Eng. Part H J. Eng. Med. 1989, 203, 187-190. [CrossRef]

142. McErlain-Naylor, S.A.; King, M.A.; Allen, S.J. Surface acceleration transmission during drop landings in humans. J. Biomech. 2021, 110269. [CrossRef]

143. Poulton, E.C. On prediction in skilled movements. Psychol. Bull. 1957, 54, 467-478. [CrossRef]

144. Corbetta, D.; Vereijken, B. Understanding development and learning of motor coordination in sport: The contribution of dynamic systems theory. Int. J. Sport Psychol. 1999, 30, 507-530.

145. Zanone, P.G.; Kelso, J.A. Evolution of behavioral attractors with learning: Nonequilibrium phase transitions. J. Exp. Psychol. Hum. Percept. Perform. 1992, 18, 403-421. [CrossRef]

146. Kelso, J.A. Phase transitions and critical behavior in human bimanual coordination. Am. J. Physiol. Integr. Comp. Physiol. 1984, 246, R1000-R1004. [CrossRef]

147. Yamamoto, K.; Shinya, M.; Kudo, K. The influence of attractor stability of intrinsic coordination patterns on the adaptation to new constraints. Sci. Rep. 2020, 10, 3058. [CrossRef] [PubMed]

148. Kostrubiec, V.; Zanone, P.-G.; Fuchs, A.; Kelso, J.A.S. Beyond the blank slate: Routes to learning new coordination patterns depend on the intrinsic dynamics of the learner-experimental evidence and theoretical model. Front. Hum. Neurosci. 2012, 6, 222. [CrossRef] [PubMed]

149. Davids, K.; Glazier, P.; Araújo, D.; Bartlett, R. Movement systems as dynamical systems. Sport. Med. 2003, 33, 245-260. [CrossRef]

150. Hiley, M.J.; Yeadon, M.R. Investigating optimal technique in a noisy environment: Application to the upstart on uneven bars. Hum. Mov. Sci. 2013, 32, 181-191. [CrossRef] [PubMed]

151. Hiley, M.J.; Yeadon, M.R. Achieving consistent performance in a complex whole body movement: The Tkatchev on high bar. Hum. Mov. Sci. 2012, 31, 834-843. [CrossRef]

152. Hiley, M.J.; Yeadon, M.R. Investigating optimal technique in the presence of motor system noise: Application to the double layout somersault dismount on high bar. J. Sports Sci. 2016, 34, 440-449. [CrossRef] [PubMed]

153. Hiley, M.J.; Yeadon, M.R. What governs successful performance of a complex whole body movement: The Kovacs release-regrasp on horizontal bar? J. Biomech. 2016, 49, 3971-3976. [CrossRef]

154. Hiley, M.J.; Yeadon, M.R. Determining the solution space for a coordinated whole body movement in a noisy environment: Application to the upstart in gymnastics. J. Appl. Biomech. 2014, 30, 508-513. [CrossRef] [PubMed]

155. Hicks, J.L.; Uchida, T.K.; Seth, A.; Rajagopal, A.; Delp, S.L. Is my model good enough? Best practices for verification and validation of musculoskeletal models and simulations of movement. J. Biomech. Eng. 2015, 137, 020905. [CrossRef] [PubMed] 
156. Hiley, M.J.; Yeadon, M.R. Optimum technique for generating angular momentum in accelerated backward giant circles prior to a dismount. J. Appl. Biomech. 2003, 19, 119-130. [CrossRef]

157. Harrison, A.J.; McErlain-Naylor, S.A.; Bradshaw, E.J.; Dai, B.; Nunome, H.; Hughes, G.T.G.; Kong, P.W.; Vanwanseele, B.; Vilas-Boas, J.P.; Fong, D.T.P. Recommendations for statistical analysis involving null hypothesis significance testing. Sport. Biomech. 2020, 19, 561-568. [CrossRef]

158. Caldwell, A.R.; Vigotsky, A.D.; Tenan, M.S.; Radel, R.; Mellor, D.T.; Kreutzer, A.; Lahart, I.M.; Mills, J.P.; Boisgontier, M.P. Moving sport and exercise science forward: A call for the adoption of more transparent research practices. Sport. Med. 2020, 50, 449-459. [CrossRef] [PubMed]

159. Büttner, F.; Toomey, E.; McClean, S.; Roe, M.; Delahunt, E. Are questionable research practices facilitating new discoveries in sport and exercise medicine? The proportion of supported hypotheses is implausibly high. Br. J. Sports Med. 2020, 54, 1365-1371. [CrossRef] [PubMed]

160. Bernards, J.; Sato, K.; Haff, G.; Bazyler, C. Current research and statistical practices in sport science and a need for change. Sports 2017, 5, 87. [CrossRef] [PubMed]

161. Sayyah, M.; King, M.A.; Hiley, M.J.; Yeadon, M.R. Functional variability in the takeoff phase of one metre springboard forward dives. Hum. Mov. Sci. 2020, 72, 102634. [CrossRef] [PubMed]

162. Yeadon, M.R.; Mikulcik, E.C. The control of non-twisting somersaults using configuration changes. J. Biomech. 1996, 29 , 1341-1348. [CrossRef]

163. Corana, A.; Marchesi, M.; Martini, C.; Ridella, S. Minimizing multimodal functions of continuous variables with the "simulated annealing" algorithm. ACM Trans. Math. Softw. 1987, 13, 262-280. [CrossRef]

164. Carroll, D.L. Genetic algorithms and optimizing chemical oxygen-iodine lasers. Dev. Theor. Appl. Mech. 1996, 18, 411-424.

165. Dembia, C.L.; Bianco, N.A.; Falisse, A.; Hicks, J.L.; Delp, S.L. OpenSim Moco: Musculoskeletal optimal control. PLOS Comput. Biol. 2020, 16, e1008493. [CrossRef] [PubMed]

166. De Groote, F.; Kinney, A.L.; Rao, A.V.; Fregly, B.J. Evaluation of direct collocation optimal control problem formulations for solving the muscle redundancy problem. Ann. Biomed. Eng. 2016, 44, 2922-2936. [CrossRef] [PubMed]

167. Falisse, A.; Serrancolí, G.; Dembia, C.L.; Gillis, J.; Jonkers, I.; De Groote, F. Rapid predictive simulations with complex musculoskeletal models suggest that diverse healthy and pathological human gaits can emerge from similar control strategies. J. R. Soc. Interface 2019, 16, 20190402. [CrossRef]

168. Baumann, W. Biomechanics of sports-Current problems. In Biomechanics: Basic and Applied Research; Bergmann, G., Kölbel, R., Rohlmann, A., Eds.; Springer: Dordrecht, The Netherlands, 1987; pp. 51-58.

169. Waters, A.; Phillips, E.; Panchuk, D.; Dawson, A. The coach-scientist relationship in high-performance sport: Biomechanics and sprint coaches. Int. J. Sports Sci. Coach. 2019, 14, 617-628. [CrossRef]

170. Hiley, M.J. Coaching biomechanics interface: Simulation modelling. In Proceedings of the XXVIII International Symposium of Biomechanics in Sports, Marquette, MI, USA, 19-23 July 2010; pp. 112-115.

171. Waters, A.; Panchuk, D.; Phillips, E.; Dawson, A. Experiential knowledge affects the visual search behaviors of sprint coaches and sport biomechanists. Front. Sport. Act. Living 2020, 2, 95. [CrossRef] [PubMed]

172. Waters, A.; Phillips, E.; Panchuk, D.; Dawson, A. Coach and biomechanist experiential knowledge of maximum velocity sprinting technique. Int. Sport Coach. J. 2019, 6, 172-186. [CrossRef]

173. Elliott, B.; Bartlett, R. Sports biomechanics: Does it have a role in coaching? Int. J. Sports Sci. Coach. 2006, 1, 177-183. [CrossRef]

174. Vaughan, C.L. Computer simulation of human motion in sports biomechanics. In Exercise and Sport Sciences Reviews; Terjung, R.L., Ed.; Collamore Press: Lexington, MA, USA, 1984; pp. 373-416.

175. Liu, Y.-T.; Newell, K.M. Individual pathways of change in motor learning and development. In Complex Systems in Sport; Davids, K., Hristovski, R., Araújo, D., Balagué Serre, N., Button, C., Passos, P., Eds.; Routledge: London, UK, 2014; pp. $293-305$.

176. Fleisig, G.S.; Diffendaffer, A.Z.; Ivey, B.; Aune, K.T. Do baseball pitchers improve mechanics after biomechanical evaluations? Sport. Biomech. 2018, 17, 314-321. [CrossRef] [PubMed] 